Externality of risk and crash severity at roundabouts

Peer-reviewed author version

DANIELS, Stijn; BRIJS, Tom; NUYTS, Erik \& WETS, Geert (2010) Externality of risk and crash severity at roundabouts. In: ACCIDENT ANALYSIS AND PREVENTION, 42 (6). p. 1966-1973.

DOI: 10.1016/j.aap.2010.06.001

Handle: http://hdl.handle.net/1942/11292 


\section{Title: Externality of risk and crash severity at roundabouts}

Authors: Stijn Daniels ${ }^{1 \circ}$, Tom Brijs ${ }^{1}$, Erik Nuyts ${ }^{2}$, Geert Wets ${ }^{1}$

${ }^{1}$ Hasselt University - Transportation Research Institute

Wetenschapspark 5 bus 6, 3590 Diepenbeek, Belgium

Tel. +3211269111 Fax +3211269199

e-mail \{stijn.daniels; tom.brijs; geert.wets\}@uhasselt.be

2 PHL University College - Architecture, Art and Design Research Institute

Universitaire Campus Building E, 3590 Diepenbeek, Belgium

Tel. +3211249213 e-mail erik.nuyts@phl.be

${ }^{\circ}$ Corresponding author

Key words: roundabout, crash severity, logistic regression, multilevel, externality 


\section{ABSTRACT}

The severity of 1491 crashes on 148 roundabouts in Flanders-Belgium was examined in order to investigate which factors might explain the severity of crashes or injuries and to relate these factors to the existing knowledge about contributing factors for injury severity in traffic. Logistic regression and hierarchical binomial logistic regression techniques were used.

A clear externality of risk appeared to be present in the sense that vulnerable road user groups (pedestrians, bicyclists, moped riders and motorcyclists) are more severely affected than others. Fatalities or serious injuries in multiple-vehicle crashes for drivers of four-wheel vehicles are much rarer.

Injury severity increases with higher age. Crashes at night and crashes outside built-up areas are more severe. Single-vehicle crashes seem to have more severe outcomes than multiplevehicle crashes. However, systematic differences in the reporting rate of crashes are likely to exist and may have affected the stated results. Correlations with important, but unobserved variables like the impact speeds in the crashes might exist as well and could provide an alternative explanation for some results. 


\section{INTRODUCTION}

Traffic safety aspects of roundabouts have been investigated earlier. Generally, it was found that roundabouts are able to reduce injury crashes considerably, although not for all user groups (Daniels et al., 2008; 2009; Elvik, 2003; Persaud et al., 2001). In a previous analysis by the same authors, crash prediction models were fit for all injury crashes at roundabouts (Daniels et al., 2010.). The results showed that vulnerable road users (moped riders, motorcyclists, bicyclists and pedestrians) are more frequently than expected involved in crashes at roundabouts. Roundabouts with cycle lanes close to the roadway were clearly performing worse than roundabouts with off-road cycle paths. Nevertheless, the variation in crash rates at the examined roundabouts was relatively small and mainly explained by the traffic exposure. Furthermore confirmation was found for the existence of a safety in numberseffect for bicyclists, moped riders and - unsure - for pedestrians at roundabouts.

In this paper, the focus is on the level of severity of crashes that were recorded at roundabouts. Severity can be expressed as the probability that, when a crash happens, the outcome will be of certain seriousness. The objective of the present research was to investigate which factors might explain the severity of crashes and injuries at roundabouts and to relate these factors to the existing knowledge on explaining factors for injury severity in traffic.

The remainder of the paper is organized as follows. The next section describes the data that were collected and the way it was done. Subsequently the different analysis methods and levels are described and the results are provided. Finally the results are discussed and conclusions are drawn.

\section{DATA COLLECTION}

Information was available on crashes at 148 roundabouts on regional roads in Flanders-Belgium. The dataset departed from a previously composed dataset of 90 roundabouts (Daniels et al., 2010), that was extended. Each roundabout in the sample was visited and photographed, traffic counts were executed and geometric data were collected on the spot. Information on the construction year of the roundabout was available from the Roads and Traffic Agency's database. All investigated roundabouts were constructed between 1990 and 2002. The collected variables are listed in Table 1. 
Traffic data were collected as follows: at each examined roundabout all entering traffic was counted by one or two observers during $1 \mathrm{~h}$ by day (between 8:00 and 18:00). Traffic modes were classified in light vehicles, heavy vehicles, motorcycles, mopeds, bicycles and pedestrians. Light vehicles comprised mainly private cars, but also minibuses and all kinds of vans. Heavy vehicles were trucks, trailers, busses and tractors. Calibration counts were held on two roundabouts during one day (08:0018:00). The results of the calibration counts were used to calculate adjustment factors that brought all the hourly traffic counts to a common $10 \mathrm{~h}$ (08:00-18:00) level. Subsequently, the counts for private cars, heavy vehicles and motorcycles were added up in order to estimate a value for the Average Daily Traffic (ADT), representing the motorized, fast traffic. The calculated ADT-values thus represent the traffic volume during a daytime period of 10 hours. It was assumed that the derived value for the $10 \mathrm{~h}$ daytime traffic is a valid indicator for the relative $24 \mathrm{~h}$ traffic volume for each location, i.e. for the locations compared with each other. Differently stated, this means that it was assumed that the proportion of daytime or night time traffic in the total traffic at the observed locations is more or less constant. This assumption is justified by the fact that the share of daytime traffic between 8:00 and 18:00 in the total daily ( 24 hour) traffic on locations were extensive traffic volume data are available for, i.e. segments of regional N-roads, is $61.35 \%$, with a standard deviation of only $2.33 \%$ (AWV, 2008). No particular reason seems to exist why this share and standard deviation would be different at roundabouts. Although the inference of ADT-values from counts during one hour brought an amount of uncertainty in the analyses, this approach enabled to obtain a useful classification of the sample of roundabouts according to their traffic volume.

The 148 roundabout locations were localised and geo-coded in Google Earth. Subsequently the roundabout data were linked in a geographical information system (ArcMap) with the geo-referenced crash data (available from Statistics Belgium) for the period 1996-2005. All crashes within a distance of 100 meters of the centre of the roundabout were included in the dataset. After subtraction of the crashes that occurred before the roundabouts were constructed, the dataset consisted of 1491 injury crashes. This means that the used period of crash data differed from location to location. The mean number of crashes per year per roundabout (see Table 2) was calculated as follows: firstly we determined for each roundabout the number of years where we had crash data available for (minimum 
3, maximum 10, on average 8.03 years). We called this value the "analysis period". The number of crashes per location in the entire analysis period appeared to vary between 0 and 57 . Subsequently we divided the number of crashes in the entire analysis period for each roundabout to the length (in years) of the analysis period. The average of these values for the 148 roundabouts was 1.22 (SD 1.15). The other values in Table 2 were derived in an identical way.

Like in most European countries, the Belgian crash data distinct between 3 levels: crashes resulting in fatal injuries (at least someone in the crash killed immediately or - as a consequence of the crash within 30 days after the crash), crashes resulting in serious injuries (at least someone in the crash was seriously injured, i.e. in a hospital for at least 24 hours) and crashes with slight injuries (any type of injuries, but not belonging to one of the previous categories) (European Commission, 2006; FOD Economie, 2009). Apart from the crash level, analyses were done as well on the subject level, i.e. all the involved road users in the examined crashes. 
Table 1 Explanatory variable description

\begin{tabular}{|c|c|c|}
\hline Variable (ABBREVIATION) & $\begin{array}{c}\text { Number of } \\
\text { observations }\end{array}$ & Descriptive statistics \\
\hline Inside the built-up area? (INSIDE) $(1=$ Yes; $0=$ No, thus outside) & 148 & Yes: 55; No: 93 \\
\hline Central island min. $0.5 \mathrm{~m}$ raised? $(\mathrm{ELEV})(1=\mathrm{Yes} ; 0=\mathrm{No})$ & 148 & Yes: $115 ;$ No: 33 \\
\hline Traversable truck apron present? (APRON) $(1=$ Yes; $0=$ No $)$ & 148 & Yes: $141 ;$ No: 7 \\
\hline Central island diameter (in meters) (CENTRDIAM) & 148 & Mean: 25.22; S.D.: 12.30 \\
\hline Inscribed circle diameter (in meters) (OUTDIAM) & 148 & Mean: 40.29; S.D.: 12.85 \\
\hline Number of legs (3LEG, 4LEG, 56LEG) $(1=$ Yes; $0=$ No $)$ & 148 & $\begin{array}{l}\text { 3-leg: 32; 4-leg:100; 5-or 6-leg: } \\
16\end{array}$ \\
\hline $\begin{array}{l}\text { Gated roadway through the central island? }(\text { EXCEPT })(1=\text { Yes; } 0= \\
\text { No) }\end{array}$ & 148 & Yes: 4 ; No: 144 \\
\hline Bypass present in some directions? (BYPASS) $(1=$ Yes; $0=\mathrm{No})$ & 148 & Yes: 22; No: 126 \\
\hline Oval roundabout? $(\mathrm{OVAL})(1=\mathrm{Yes} ; 0=\mathrm{No})$ & 148 & Yes: 8; No: 140 \\
\hline $\begin{array}{l}\text { Two-lane roundabout? }(\text { TWOLANE) }(1=\text { Yes; } 0=\text { No, thus single- } \\
\text { lane) }\end{array}$ & 148 & Yes: 15; No: 133 \\
\hline $\begin{array}{l}\text { Road with on the roundabout (all lanes together, in meters) } \\
\text { (ROADWIDTH) }\end{array}$ & $\begin{array}{c}133 \\
15\end{array}$ & $\begin{array}{l}\text { Mean: } 6.38 \text {; S.D.: } 1.26 \text { (single- } \\
\text { lanes) } \\
\text { Mean: } 7.78 \text {; S.D.: } 1.41 \text { (two- } \\
\text { lanes) }\end{array}$ \\
\hline Construction year of the roundabout (YEAR) & 148 & $\begin{array}{l}\text { Median: 1996; range } \\
{[1990 ; 2002]}\end{array}$ \\
\hline Mixed Traffic? (MIXED) $(1=$ Yes; $0=$ No $)$ & 148 & Yes: 13 ; No: 135 \\
\hline Cycle lanes close to the roadway? (CYCLLANE) $(1=$ Yes; $0=$ No $)$ & 148 & Yes: $64 ;$ No: 84 \\
\hline $\begin{array}{l}\text { Cycle paths, separated from the roadway? (CYCLPATH) }(1=\text { Yes; } 0 \\
=\text { No) }\end{array}$ & 148 & Yes: 66 ; No: 82 \\
\hline Grade-separated cycle facilities ? (GRADESEP) $(1=$ Yes; $0=$ No $)$ & 148 & Yes: 4; No: 144 \\
\hline $\begin{array}{l}\text { Sidewalk present around the roundabout? (SIDEWALK) }(1=\text { Yes; } 0= \\
\text { No) }\end{array}$ & 148 & Yes: 71 ; No: 77 \\
\hline $\begin{array}{l}\text { Zebra markings present on exit/entry lanes? (ZEBRA) }(1=\text { Yes; } 0= \\
\text { No) }\end{array}$ & 148 & Yes: 75 ; No: 73 \\
\hline Nr. of pedestrians 8:00-18:00 (PED) & 148 & Mean: 246; S.D.: 645 \\
\hline Nr. of bicyclists 8:00-18:00 (BIC) & 148 & Mean: 470; S.D.: 765 \\
\hline Nr. of mopeds 8:00-18:00 (MOP) & 148 & Mean: 76; S.D.: 108 \\
\hline Nr. of motorcycles 8:00-18:00 (MCY) & 148 & Mean: 98; S.D.: 260 \\
\hline Nr. of light vehicles 8:00-18:00 (LGT) & 148 & Mean: 11627; S.D.: 5818 \\
\hline Nr. of heavy vehicles 8:00-18:00 (HVY) & 148 & Mean: 1155; S.D.:1237 \\
\hline
\end{tabular}

Table 2 Average annual injury crash rates per roundabout $(\mathrm{N}=148)$

\begin{tabular}{|c|c|c|}
\hline Per roundabout, annual average number of & Mean & Variance \\
\hline injury all crashes & 1.22 & 1.33 \\
\hline crashes with light vehicles & 1.04 & 1.08 \\
\hline crashes with bicyclists & 0.33 & 0.17 \\
\hline crashes with moped riders & 0.21 & 0.13 \\
\hline crashes with heavy vehicles & 0.09 & 0.02 \\
\hline crashes with motorcycles & 0.08 & 0.01 \\
\hline crashes with pedestrians & 0.05 & 0.01 \\
\hline single-vehicle crashes & 0.29 & 0.26 \\
\hline multiple-vehicle crashes & 0.92 & 0.94 \\
\hline
\end{tabular}


Table 3 shows frequency statistics of the crash data, related to the number of involved road users. Most dominant are the crashes with only one involved vehicle (single-vehicle crashes) (22\%) and twovehicle crashes (72\%). Table 4 shows the frequency of injuries of different levels both for the singlevehicle crashes and the multiple-vehicle collisions. Car occupants account for most of the killed and severely injured in single-vehicle crashes, whereas the two-vehicle crash data show particularly a considerable proportion of bicyclists among the killed. All the transport modes that are listed in the table are legally considered to be vehicles, except for pedestrians. Crashes with only pedestrians (e.g. falls) are legally considered to be no traffic crashes. Pedestrians are therefore not present in the examined single-vehicle crash data. However, in the case of a crash with one vehicle and a pedestrian, we considered it to be a multiple-vehicle crash since at least two human actors were involved.

Table 3 Frequency statistics of crashes in the roundabout dataset according to number of involved parties

\begin{tabular}{|c|r|}
\hline $\begin{array}{c}\text { Number of } \\
\text { involved parties }\end{array}$ & $\begin{array}{c}\text { Number of } \\
\text { crashes }\end{array}$ \\
\hline 1 & 322 \\
\hline 2 & 1068 \\
\hline 3 & 95 \\
\hline 4 & 6 \\
\hline$\sum$ & 1491 \\
\hline
\end{tabular}

Table 4 Frequency of injuries in the dataset ${ }^{1}$

\begin{tabular}{|l|c|c|c|c|c|}
\hline Travel mode & Killed & $\begin{array}{c}\text { Seriously } \\
\text { injured }\end{array}$ & $\begin{array}{c}\text { Lightly } \\
\text { injured }\end{array}$ & Not injured & SUM \\
\hline Bicycle & $0 ; 12$ & $6 ; 47$ & $11 ; 325$ & $0 ; 17$ & $17 ; 401$ \\
\hline Light vehicle & $5 ; 1$ & $45 ; 24$ & $157 ; 424$ & $27 ; 1034$ & $234 ; 1483$ \\
\hline Heavy vehicle & $1 ; 0$ & $2 ; 0$ & $13 ; 6$ & $2 ; 91$ & $18 ; 97$ \\
\hline Moped & $0 ; 1$ & $5 ; 17$ & $17 ; 210$ & $1 ; 18$ & $23 ; 246$ \\
\hline Motorcycle & $2 ; 2$ & $7 ; 6$ & $36 ; 35$ & $2 ; 3$ & $47 ; 46$ \\
\hline Pedestrian & $0 ; 1$ & $0 ; 17$ & $0 ; 38$ & $0 ; 4$ & $0 ; 60$ \\
\hline Other & $1 ; 0$ & $0 ; 0$ & $3 ; 23$ & $3 ; 6$ & $7 ; 29$ \\
\hline SUM & $9 ; 17$ & $65 ; 111$ & $237 ; 1061$ & $35 ; 1173$ & $346 ; 2362$ \\
\hline
\end{tabular}

${ }^{1}$ Represented values $=\mathrm{x}$; $\mathrm{y}$ with $\mathrm{x}=$ absolute number in single-vehicle crashes, $\mathrm{y}=$ absolute number in multiplevehicle crashes 
Basic goal of this study was to explore the crash severity at roundabouts. In the next section this is done in a rather intuitive way, whereas in the subsequent sections regression models are applied in order to establish formal relationships in the data. A distinction is made between severity on the crash level and on the subject level (= for those who were involved in the crash).

\section{RISK EXTERNALITY}

In general, an externality is present whenever some economic agent's (Y's) welfare (utility or profit) function includes real variables whose values are chosen directly by others (X) without particular attention to the effect upon the welfare of agent Y they affect (Schipper et al., 2001). Applied to traffic safety, the concept of externality can be described as the fact that travel performed by one group of road users imposes an additional risk on other groups of road users (Elvik, 2008).

Table 5 and Table 6 provide descriptive statistics of the concept of externality, applied to the multiplevehicle crashes in the dataset, for the severest injuries (seriously or fatally injured) and for all injuries respectively. E.g. the value 35/3 in Table 6 for the combination light vehicles / heavy vehicles means that 35 drivers of light vehicles were at least slightly injured in collisions with heavy vehicles while in the same collisions 3 drivers of heavy vehicles were injured.

For the purpose of describing the externality concept in this section and in the analyses on the subject level in section 5, only information on the driver's injuries (thus not for the passengers) was included. This was done in order to eliminate random effects of the number of passengers and in order to enable the analyses on a variable such as ALCOHOL (reflecting the result of an alcohol test) that was only available for drivers. Crashes with more than two involved parties were principally included as well. If only two different road user categories were involved in these crashes, the collision was considered to have happened between the two different parties. If, for instance, a collision occurred between a car and two moped riders, the crash was considered to have happened between a moped rider and a car. If more than two different road user types were involved in the same crash, the crash was not included in Table 5 and Table 6 since no detailed information was available about the course of the crash, which 
hindered a correct assignment of the crash to one or another category. The tables show that only a few crashes belonged to this last category.

Table 5 Externality of risk - Number of killed or seriously injured in two-party collisions ${ }^{1}$

\begin{tabular}{|l|c|c|c|c|c|c|}
\hline Killed or seriously injured in/on/as & $\begin{array}{c}\text { Heavy } \\
\text { vehicle }\end{array}$ & $\begin{array}{c}\text { Light } \\
\text { vehicle }\end{array}$ & Motorcycle & Moped & Bicycle & TOTAL \\
\hline Heavy vehicle & 0 & & & & & 0 \\
\hline Light vehicle & $6 / 0$ & 19 & & & & 8 \\
\hline Motorcycle & $2 / 0$ & $6 / 0$ & 0 & & & 17 \\
\hline Moped & $1 / 0$ & $15 / 0$ & $0 / 0$ & 1 & 59 \\
\hline Bicycle & $10 / 0$ & $46 / 0$ & $1 / 0$ & $2 / 0$ & 0 & 18 \\
\hline Pedestrian & $1 / 0$ & $14 / 0$ & $1 / 0$ & $1 / 0$ & $1 / 0$ & $\sum=127$ \\
\hline
\end{tabular}

${ }^{1}$ Presented values $\mathrm{x} / \mathrm{y}$ with $\mathrm{x}=$ killed or seriously injured as driver/rider of (row) in collisions with (column) and $\mathrm{y}=$ killed or seriously injured as driver/rider of (column) in collisions with (row). 1 seriously injured moped rider in a three-vehicle crash (car-truck-moped) was not included.

Table 6 Externality of risk - Number of injured in two-party collisions ${ }^{1}$

\begin{tabular}{|l|c|c|c|c|c|c|}
\hline Killed or injured in/on/as & $\begin{array}{c}\text { Heavy } \\
\text { vehicle }\end{array}$ & $\begin{array}{c}\text { Light } \\
\text { vehicle }\end{array}$ & Motorcycle & Moped & Bicycle & TOTAL \\
\hline & & & & & & 6 \\
\hline Heavy vehicle & 3 & & & & & 449 \\
\hline Light vehicle & $35 / 3$ & 405 & & & & 43 \\
\hline Motorcycle & $3 / 0$ & $35 / 2$ & 0 & & & 224 \\
\hline Moped & $11 / 0$ & $185 / 3$ & $3 / 2$ & 10 & & 382 \\
\hline Bicycle & $29 / 0$ & $316 / 2$ & $3 / 3$ & $20 / 11$ & 12 & $56 / 2$ \\
\hline Pedestrian & $4 / 0$ & $37 / 2$ & $1 / 0$ & $8 / 4$ & $6 / 2$ & \\
\hline
\end{tabular}

${ }^{1}$ Presented values $\mathrm{x} / \mathrm{y}$ with $\mathrm{x}=$ killed or injured as driver/rider of (row) in collisions with (column) and $\mathrm{y}=$ killed or injured as driver/rider of (column) in collisions with (row). 23 injured in categories other/unknown and 6 injured in crashes with more than two different road user types were not included.

Table 5 shows that bicyclists represent almost the half of all the killed or seriously injured in multiplevehicle collisions at the investigated roundabouts. Furthermore, the tables show imbalances between 
the injury severities according to the different road user types. When only the severest injuries are considered as it is the case in Table 5, the injured is always the occupant of the lightest vehicle. When all injuries in the crash are considered (Table 6), this phenomenon persists although somewhat less explicit.

\section{SEVERITY AT THE CRASH LEVEL}

On the crash level, the severity is expressed as the severity of the worst injury that was reported in the crash, regardless of the question which party was affected or what was the role of the involved (driver/rider or passenger). The objective was to check which factors would influence the severity of the crash. Variables related to the crash (e.g. type and number of involved road users, light conditions) as well as variables related to the roundabout (e.g. number of legs, inscribed circle diameter, type of cycle facilities) were available. These characteristics can be assumed to represent a hierarchical data structure whereby observations (=crashes) within the same group (= on the same roundabout) are more alike than crashes across groups. Consequently, correlations might exist among crashes occurring at the same roundabout, since these crashes may share (possibly unobserved) characteristics of the roundabout.

Logistic regression analyses have often been used to model crash severity. One of the prerequisites of a traditional logistic regression framework is that the residuals from the model are independent across observations (Verbeek, 2004). However, the observations in the used dataset might correlate within the groups (= roundabouts). Therefore a hierarchical 2-level binomial logistic model was adopted like proposed by Kim et al. (2007).

The structure of the fitted model was the following:

$$
\begin{array}{ll}
\text { Let } & \text { binary outcome variable for the } \mathrm{i}^{\text {th }} \text { crash on roundabout } \mathrm{j} \\
\mathrm{Y}_{\mathrm{ij}} & \text { probability of the resulting binomial }(0,1) \text { outcome } \mathrm{Y}_{\mathrm{ij}} \\
p_{i j}=\sum Y_{i j} / \mathrm{n} & \text { model parameters, } \\
\beta_{\mathrm{p}}, \gamma_{0}, \gamma_{\mathrm{q}} & \text { covariates }\left(\mathrm{X}_{1}, \ldots, \mathrm{X}_{\mathrm{P}}\right) \text { at the crash level } \\
\mathrm{X}_{\mathrm{pij}} &
\end{array}
$$




$$
\begin{aligned}
& \mathrm{R}_{\mathrm{qj}} \quad \text { covariates }\left(\mathrm{R}_{1}, \ldots, \mathrm{R}_{\mathrm{Q}}\right) \text { at the roundabout level } \\
& u_{j} \quad \text { random effect at the roundabout level } \mathrm{u}_{\mathrm{j}} \sim \mathrm{N}\left(0, \sigma_{\mathrm{u}}^{2}\right)
\end{aligned}
$$

Then

$$
\begin{array}{ll}
\operatorname{LN}\left(\frac{\mathrm{p}_{\mathrm{ij}}}{1-\mathrm{p}_{\mathrm{ij}}}\right)=\alpha_{\mathrm{j}}+\sum_{\mathrm{p}=1}^{\mathrm{P}} \beta_{\mathrm{p}} \cdot \mathrm{X}_{\mathrm{pij}} & \text { (level 1-model) } \\
\text { And } \alpha_{\mathrm{j}}=\gamma_{0}+\sum_{\mathrm{q}=1}^{\mathrm{Q}} \gamma_{\mathrm{q}} \cdot \mathrm{R}_{\mathrm{qj}}+\mathrm{u}_{\mathrm{j}} & \text { (level 2-model) }
\end{array}
$$

The multilevel model was fitted by the use of the GLIMMIX procedure in SAS 9.2. Dependent variable was the probability that the outcome of the crash, measured as the most severe injury reported in the crash, was either fatal or at least serious $\left(\mathrm{Y}_{\mathrm{ij}}=1\right)$ or not $\left(\mathrm{Y}_{\mathrm{ij}}=0\right)$. A forward stepwise regression procedure was adopted. Odds-ratios $\left(\mathrm{OR}=\mathrm{e}^{\beta_{\mathrm{p}}}\right.$ or $\left.\mathrm{e}^{\gamma_{\mathrm{q}}}\right)$ were calculated to determine the rate of increase $(O R>1)$ or decrease $(0 \leq \mathrm{OR}<1)$ of the probability of the outcome when the value of the independent variables $X_{\mathrm{pj}}$ or $\mathrm{R}_{\mathrm{qj}}$ increases with one unit. Values further away from 1 represent stronger associations. In case $\mathrm{OR}=1$, the outcome is independent of the variable $\mathrm{X}_{\mathrm{p}}$ or $\mathrm{R}_{\mathrm{q}}$.

The results are provided in Table 7. The table shows the odds-ratios and their significance values (measuring the result of the hypothesis test $\mathrm{H}_{0}$ : $\mathrm{OR}=1$ ). Two models are presented: the first reflecting the likelihood of having a fatal or serious injury in the crash, the second with the probability of a fatally injured in the crash. Values that are significant at the level $p \leq 0.05$ are printed in bold. After fitting both models separately, all variables that were significant at the 5\%-level in one of both models were included in the other model as well. This approach allowed to assess the consistency of some results over the two categories and to obtain as much information from the data as possible. It should be noticed that fitting a model with too many covariates in case of an event only occurring in a few cases (like in $\mathrm{Y}=$ killed, where $\mathrm{Y}=1$ occurs only in 27 of 1491 observations), might lead to biased estimations and poor standard errors (Agresti, 2002). The results of the model for Y=killed should therefore be interpreted with much caution. The results show that the probability of a killed or at least a seriously injured in the crash increases rather consistently in case of single-vehicle crashes (SINGLE) or in crashes wherein a pedestrian (PEDESTRIAN), a bicyclist (BICYCLIST), a truck or 
bus (HEAVY) or a motorcyclist (MOTORCYCLE) is involved. Moreover the severity seems to increase in case of a roundabout with grade-separated cycle facilities (GRADESEP) and in case of a crash at night on locations without street lighting. Furthermore, a larger inscribed circle diameter (OUTDIAM) of the roundabout could be somewhat more protective in case of a crash, but this result is highly uncertain.

The intra-class correlation coefficient $\rho$ expresses the proportion of residual variability that is associated with the level 2 (roundabout) unit. It is calculated according to the procedure described in Kim et al. (2007) and Goldstein et al. (2002) and uses the variance of the residuals from the level 2 model $\left(\sigma_{u}^{2}\right)$ and the variance of the residuals of the level 1 model $\left(\sigma_{e}^{2}\right)$ :

$$
\rho=\frac{\sigma_{u}^{2}}{\sigma_{u}^{2}+\sigma_{e}^{2}}
$$

A higher value of $\rho$ indicates a stronger clustering of the data according to the units (roundabouts) in level 2. The results in Table 7 ( $\rho$ of 0.04 and 0.08 ) show that the variance between the level 2 units explains only a small part of the total variance. This suggests that no real hierarchical structure is present in the data. 
Table 7 Hierarchical binomial logistic regression results for the odds of $Y=1$ in the crash $(N=1491)$

\begin{tabular}{|c|c|c|}
\hline & $\begin{array}{c}\text { Y = Killed or severely } \\
\text { injured } \\
\text { Odds ratio }[95 \% \text { C.I. }] \\
\text { (p-value) }\end{array}$ & $\begin{array}{c}\text { Y }=\text { Killed } \\
\text { Odds ratio }[95 \% \text { C.I. }] \text { (p-value) }\end{array}$ \\
\hline \multicolumn{3}{|l|}{ Level 1 - crash } \\
\hline BICYCLIST = Yes vs. No & $\mathbf{2 . 1 6}[1.48-3.14](<0.01)$ & $4.42[1.62-12.03](<0.01)$ \\
\hline PEDESTRIAN = Yes vs. No & $\mathbf{4 . 7 6}[2.56-8.83](<0.01)$ & $2.28[0.26-19.93](0.46)$ \\
\hline HEAVY vehicle $=$ Yes vs. No & $\mathbf{2 . 1 6}[1.30-3.58](<0.01)$ & $14.75[6.01-36.20](<0.01)$ \\
\hline MOTORCYCLE = Yes vs. No & $1.51[0.86-2.68](0.15)$ & $4.23[1.18-15.23](0.03)$ \\
\hline SINGLE-vehicle $=$ Yes vs. No & $3.26[2.21-4.82](<0.01)$ & $5.21[1.88-14.42](<0.01)$ \\
\hline \multicolumn{3}{|l|}{ LIGHT conditions $^{1}$} \\
\hline Dawn, dusk & $0.52[0.23-1.18](0.12)$ & \\
\hline Night - street lighting on & $1.20[0.83-1.74](0.34)$ & \\
\hline Night - no street lighting & $7.29[2.20-24.22](<0.01)$ & \\
\hline Day & Reference case & \\
\hline \multicolumn{3}{|l|}{ Level 2 - roundabout } \\
\hline OUTDIAM $^{2}$ & $1.00[0.98-1.01](0.76)$ & $\mathbf{0 . 9 4}[0.89-0.99](0.01)$ \\
\hline GRADESEP $=$ Yes vs. No & $2.30[0.73-7.28](0.16)$ & $16.46[2.73-99.08](<0.01)$ \\
\hline Observations & 1491 & 1491 \\
\hline Observed nr. of $\mathrm{Y}=1$ & 213 & 27 \\
\hline Proportion of $\mathrm{Y}=1$ & 0.14 & 0.02 \\
\hline Intra-class correlation $\rho$ & 0.04 & 0.08 \\
\hline
\end{tabular}

Including this variable in the model for $\mathrm{Y}=$ killed did not allow model convergence

2 Odds-ratio assessed as one meter offset from the mean $=41.07 \mathrm{~m}$ 


\section{SEVERITY AT THE SUBJECT LEVEL}

Models were fit on the subject level as well, i.e. on the level of the people involved in the crashes. Dependent variable was the probability that, for each subject involved as a driver/rider (of a truck, car, motorcycle, bicycle...) or a pedestrian in a crash, the outcome was a severe or fatal injury. For many crashes two or even more observations at the subject level were available, since multiple vehicle crashes were dominantly present in the dataset.

Available data on the subject level were gender, age, road user type, alcohol use and injury severity. Variables that in previous research (see the discussion part) proved to be influential on crash severity were forced into the model. Those variables were age, gender and alcohol use. Since alcohol use could only be measured for drivers and thus not for passengers, the latter one were not included in the analyses.

Again, a certain hierarchical structure could be present in the dataset and one could identify a subject level, a crash level and a roundabout level. However, structural biases due to this structure were very unlikely. The roundabout level was not likely to be more important than in the model at the crash level reflected in Table 7. At the crash level, intra-unit correlation was very unlikely, given the maximum of 4 observations for the same crash (see Table 3). Therefore, the adopted modelling procedure was a classic forward stepwise logistic regression. The results are shown in Table 8. Since only the data for drivers/riders were included, it follows by logic that the numbers of killed and severely injured in Table 8 were somewhat lower than those in the analyses on the crash level. The injury severity on the subject level appears to be affected by the road user type. Injuries for pedestrians, bicyclists, moped riders and motorcyclists seem to be significantly worse than for car drivers, whereas injuries for bus and truck drivers are - although not significantly - less severe. Age is positively related with injury severity. Single-vehicle crashes and crashes outside the built-up area have more severe outcomes than multiple-vehicle crashes or crashes inside built-up areas. A gender-effect is highly uncertain. The probability to get killed or seriously injured seems to be significantly higher when no alcohol test is executed and tends to be higher in case of a positive alcohol test. Light conditions seem to be 
influential in that sense that crashing in night conditions tends to be more serious. Comments on these results are provided in the discussion part.

A supplementary model was fitted for the odds of being killed as a consequence of the crash at the subject level. Including the same variables as the model for killed and seriously injured resulted again in a model with questionable properties (see section 4), but was done in order to enable comparisons between the two models.

\section{DISCUSSION}

We examined injury severity at different levels: subject, crash and roundabout. Throughout the analyses, some variables showed quite consistent effects on injury severity. Particularly the road user type and the number of involved in the crash (one or more) were predominantly related with the injury severity. Before drawing too simple conclusions based on this finding, attention should be given to an important limitation in the analysis of crash severity data. The number of reported crashes of a certain severity can be considered as the product of the real number of crashes of a certain severity and the reporting rate. The reporting rate is not a constant and depends on many factors such as the crash severity, road user type, time of the day, day of the week and the number of involved road users. Particularly the crash severity is a crucial element in determining the reporting rate: the more severe the crash, the higher the reporting rate (Elvik \& Mysen, 1999). Using data about reported crashes, it is therefore a priori impossible to say whether a change or a difference in crash counts (for instance between road user types A and B) reflects either a change or a real underlying difference in crash frequency or a difference in the reporting rate (Hauer, 2006). Obviously, this issue is of importance for our analyses. At least one should be aware of the consequences of possible different reporting rates according to each of the included factors in the models (age, gender, road user type, day/night crashes...). However, since not all variables are likely to be influenced to the same extent by this phenomenon, we will provide some considerations below, relate them to previous research on the issue of crash reporting and subsequently argue why some conclusions can be made or not. 
Table 8 Logistic regression results for the odds of $\mathrm{Y}=1$ on the subject level $(\mathrm{N}=2719)$

\begin{tabular}{|c|c|c|c|c|}
\hline Explanatory variable & Categories & Frequency & $\begin{array}{c}\text { Y= killed or severely injured } \\
\text { Odds ratio }[95 \% \text { C.I. }] \text { (p-value) }\end{array}$ & $\begin{array}{c}\text { Y }=\text { killed } \\
\text { Odds ratio [95\% C.I.] (p-value) }\end{array}$ \\
\hline Gender & $\begin{array}{l}\text { Male } \\
\text { Female } \\
\text { Unknown } \\
\end{array}$ & $\begin{array}{r}1807 \\
880 \\
32 \\
\end{array}$ & $\begin{array}{c}0.96[0.68-1.37](0.84) \\
\text { reference case } \\
1.83[0.12-26.98](0.66) \\
\end{array}$ & $\begin{array}{c}2.49[0.79-7.88](0.12) \\
\text { reference case } \\
<0.01[<0.01-\infty](0.99) \\
\end{array}$ \\
\hline Alcohol test & $\begin{array}{l}\text { Refused } \\
\text { Not executed } \\
\text { Positive } \\
\text { Negative } \\
\text { Unknown }\end{array}$ & $\begin{array}{r}5 \\
1650 \\
104 \\
527 \\
433\end{array}$ & $\begin{array}{c}<<0.01[0-\infty](0.98) \\
\mathbf{2 . 0 4}[1.18-3.54](0.01) \\
1.76[0.76-4.11](0.19) \\
\text { reference case } \\
\mathbf{1 . 9 4}[1.02-3.71](0.04)\end{array}$ & $\begin{array}{c}0.44[<0.01-\infty](>0.99) \\
\infty[<0.01-\infty](0.94) \\
0.24[<0.01-\infty](>0.99) \\
\text { reference case } \\
\infty[<0.01-\infty](0.94)\end{array}$ \\
\hline Light conditions & $\begin{array}{l}\text { dawn, dusk } \\
\text { night - street lighting on } \\
\text { night- no street lighting } \\
\text { day } \\
\text { Unknown }\end{array}$ & $\begin{array}{r}154 \\
606 \\
19 \\
1919 \\
21\end{array}$ & $\begin{array}{c}0.72[0.32-1.63](0.43) \\
1.42[0.97-2.11](0.08) \\
\mathbf{5 . 1 3}[1.52-17.33](0.01) \\
\text { reference case } \\
0.79[0.09-7.23](0.84)\end{array}$ & $\begin{array}{c}1.23[0.15-9.93](0.84) \\
\mathbf{3 . 4 6}[1.41-8.53](0.01) \\
<0.01[<0.01-\infty](0.99) \\
\text { reference case } \\
<0.01[<0.01-\infty](0.98)\end{array}$ \\
\hline Type of road user & $\begin{array}{l}\text { Pedestrian } \\
\text { Bicyclist } \\
\text { Moped rider } \\
\text { Motorcyclist } \\
\text { Light vehicle driver } \\
\text { Heavy vehicle driver } \\
\text { Other/unknown }\end{array}$ & $\begin{array}{r}62 \\
423 \\
272 \\
97 \\
1709 \\
115 \\
30\end{array}$ & $\begin{array}{c}\mathbf{1 5 . 4 6}[7.76-30.81](<0.01) \\
\mathbf{6 . 8 7}[4.49-10.50](<0.01) \\
\mathbf{3 . 5 4}[2.05-6.10](<0.01) \\
\mathbf{2 . 7 1}[1.41-5.22](<0.01) \\
\text { reference case } \\
0.58[0.17-1.94](0.37) \\
0.93[0.11-7.72](0.95)\end{array}$ & $\begin{array}{c}6.25[0.65-59.64](0.11) \\
\mathbf{1 0 . 5 7}[3.47-32.22](<0.01) \\
1.81[0.20-16.32](0.60) \\
\mathbf{5 . 9 0}[1.47-23.62](0.01) \\
\text { reference case } \\
2.20[0.25-19.33](0.48) \\
<0.01[<0.01-\infty](0.99)\end{array}$ \\
\hline Age & $\begin{array}{l}0-14 \\
15-29 \\
30-44 \\
45-59 \\
60-74 \\
>75 \\
\text { Unknown }\end{array}$ & $\begin{array}{r}94 \\
917 \\
786 \\
487 \\
255 \\
90 \\
90\end{array}$ & $\begin{array}{c}0.56[0.22-1.40](0.21) \\
\text { reference case } \\
1.08[0.69-1.70](0.72) \\
\mathbf{1 . 8 2}[1.15-2.87](0.01) \\
\mathbf{3 . 1 5}[1.88-5.27](<0.01) \\
\mathbf{3 . 1 0}[1.50-6.41](<0.01) \\
0.39[0.06-2.51](0.32)\end{array}$ & $\begin{array}{c}1.60[0.27-9.56](0.60) \\
\text { reference case } \\
2.19[0.69-6.93](0.18) \\
1.28[0.32-5.13](0.73) \\
2.64[0.56-12.42](0.22) \\
\mathbf{6 . 7 0}[1.36-32.95](0.02) \\
\infty[<0.01-\infty](0.98)\end{array}$ \\
\hline $\begin{array}{l}\text { Number of involved parties in the } \\
\text { crash }\end{array}$ & $\begin{array}{l}1 \\
2 \text { or more }\end{array}$ & $\begin{array}{r}346 \\
2373\end{array}$ & $\begin{array}{c}\mathbf{7 . 1 6}[4.73-10.84](<0.01) \\
\text { reference case }\end{array}$ & $\begin{array}{c}\mathbf{3 . 8 8}[1.36-11.06](0.01) \\
\text { reference case }\end{array}$ \\
\hline Built-up area & $\begin{array}{l}\text { Inside } \\
\text { Outside }\end{array}$ & $\begin{array}{l}1056 \\
1663 \\
\end{array}$ & $\begin{array}{c}\mathbf{0 . 6 6}[0.47-0.94](0.02) \\
\text { reference case }\end{array}$ & $\begin{array}{c}0.78[0.33-1.87](0.58) \\
\text { reference case }\end{array}$ \\
\hline $\begin{array}{l}\text { Summary statistics: } \\
\text { Observations } \\
\text { Observed Nr. of } \mathrm{Y}=1 \\
\text { Proportion of } \mathrm{Y}=1 \\
\text { Hosmer and Lemeshow test }\end{array}$ & & & $\begin{array}{c}2719 \\
203 \\
0.07 \\
\chi^{2}=10.88(\mathrm{df}=8, \mathrm{p}=0.21)\end{array}$ & $\begin{array}{c}2719 \\
26 \\
0.01 \\
\chi^{2}=4.86(\mathrm{df}=6, p=0.56)\end{array}$ \\
\hline
\end{tabular}




\section{Single versus multiple vehicle}

In the examined dataset, single-vehicle crashes are correlated with more severe outcomes. This might be explained by some systematic but mainly unobserved differences between single and multiple-vehicle crashes (e.g. in average crash speeds, personality traits or emotions), but a different reporting rate of single-vehicle crashes in comparison with multiple-vehicle crashes might provide an important alternative explanation. The existing literature showed consistently lower reporting rates for single vehicle crashes than for multiple vehicle crashes (Alsop \& Langley, 2001; Amoros et al., 2006; Elvik \& Mysen, 1999). Unfortunately, the magnitude of the underreporting is unclear and varies according to the involved road user type. Amoros et al. (2006) found odds ratios of 0.78, 0.32 and 0.06 for the reporting rate of single-vehicle crashes compared with multiple vehicle crashes with cars, motorcycles and bicycles respectively. With respect to our results, it is therefore impossible to conclude whether or to which degree the difference in severity between single-vehicle and multiplevehicle crashes is related to either a different reporting rate or to real existing differences in severity.

\section{Road user type}

Risk externality appeared to be dominantly present in our data, regardless of the level on which the outcomes were examined (subject or crashes). Light-weight and more vulnerable road users (pedestrians, bicyclists, moped riders and motorcyclists) are far more present in the crash statistics compared with motorised vehicles. This seems to be a clear example of the laws on mass ratio and relative driver fatality risk (Evans \& Frick, 1993) stating that (1) the lighter the vehicle, the less risk to other road users and (2) the heavier the vehicle, the less risk to its occupants.

The different models show consistently that the outcome severity of a crash is strongly dependent on the road user type. Pedestrians, bicyclists and motorcyclists have a higher probability of getting seriously injured in a crash. But again, these results may partly be attributed to differences in reporting rates according to the road user type since mainly the less severe crashes with pedestrians, bicyclists and lighter vehicles are known to be reported less (Alsop \& Langley, 2001; Amoros et al., 2006; Elvik \& Mysen, 1999). However, it should be noticed that bicyclists represent almost the half of 
all the killed or seriously injured in multiple-vehicle collisions at the investigated roundabouts, while they represent only $3.4 \%$ of the present traffic volume.

\section{Roundabout geometry}

The variables OUTDIAM (inscribed circle diameter) with odds ratio 0.94 and GRADESEP (grade-separated cycle facilities) with odds ratio 16.46 were significant in the model for $\mathrm{Y}=$ killed on the crash level, which suggested that the probability of a fatality in the crash was somewhat lower in the case of a larger roundabout and strongly higher in the case of a crash on a roundabout with gradeseparated cyclist facilities. Both results need some comments.

The role of the inscribed circle diameter could be explained by the fact that a larger obstacle free area improves the 'forgiving' capacity of a road since it provides for the same crash with the same impact more time and space for the involved vehicle(s) to slow down and therefore - according to Newtonian mechanics - reduces the amount of energy in the crash (Evans, 2004). Nevertheless, this result is unsure since the model for $\mathrm{Y}=$ killed or severely injured shows an estimated odds ratio of 1 for the variable OUTDIAM, meaning that the severity would be independent of the size of the roundabout.

The grade-separated cycle facilities (GRADESEP) showed only a significant effect in the model for $\mathrm{Y}=$ killed, but the result in the model for $\mathrm{Y}=$ killed or seriously injured showed the same tendency. Roundabouts with grade-separated cycle paths are constructed with tunnels allowing bicyclists to cross the roads without any conflict with motorised vehicles. At the first sight one would not expect a higher crash severity on this type of roundabouts. Obviously, the sparseness of this type of intersections is likely to be responsible for the large confidence intervals of the estimated odds ratios in Table 7 . The large confidence intervals reflect mainly the higher uncertainty on the estimation. Nevertheless the best estimates in the models for both severity levels are consistent and show a positive correlation between the presence of grade separated cycle facilities and a higher crash severity, which is obviously a counterintuitive result. A possible explanation for this result could be that roundabouts with gradeseparated cycle facilities are likely to be constructed in cases in which the safety of cyclists is a particular concern, which could mean that they are constructed on locations with high volumes of 
motorised traffic and/or on arterial roads with high mean speeds. Those circumstances might explain the severity of the crashes that occur. Inspection of the dataset learns that 3 people were killed on this type of roundabout whereas only 4 roundabouts were of this type (see Table 1). One of them was a private car driver in a single-vehicle crash, in two other cases motorcyclists were killed in collisions, once with a truck, another time with a private car. At least there seems to be no relation with bicycle crashes on this type of roundabouts which makes it more likely that the variable GRADESEP mainly acts as a proxy for some other, unknown variable.

\section{Alcohol use}

The results for the alcohol use deserve some extra attention. Previous research has shown that alcohol use may increase severity risk and thus not only the mere risk of a crash (Bédard et al., 2002; Waller et al., 1986), which provides a logical explanation for the tendency towards an odds ratio higher than 1 in case of a positive alcohol test. However, driving under influence is known to correlate with other behaviours such as speeding (Evans, 2004; Shinar, 2007). Since for instance speeding is not controlled for in the present study, it may on its turn be responsible for a part of the increased severity that is captured in the variable for alcohol use.

The significant positive effect in case of a not executed alcohol test needs some explanation. In a number of cases, the non execution might conceal an alcohol intoxication that was not measured or registered. This might indicate that alcohol testing is still not sufficiently a routine in case of car crashes. But another part of the explanation is likely to be related to the fact that not all victims were able to take part in the alcohol test by the police, for instance due to the severity of their injuries or due to the fact that they were carried to a hospital. The crash data don't contain information, neither on whether a subject was carried or not to a hospital nor on the particular reasons for the non execution of an alcohol test. Inspection of the data reveals that the group of 1650 subjects for who no alcohol test was executed contains 141 killed and seriously injured for who the execution of an alcohol test on the crash location was not very likely. Other, less severely injured might have been carried directly to a hospital as well, without being tested on the crash location. Results of possible blood tests in hospitals are not registered in the police data that are used for official crash reporting. 


\section{Gender and age}

In our data, gender did not show a consistent nor significant effect on the risk of serious or fatal injuries. Yet, research has found higher probabilities for females to get killed in crashes with the same impact than males (Evans, 2004). Again, the reporting rate could in the present case be somewhat influential, although most studies revealed no meaningful differences between reporting rates between males and females (Alsop \& Langley, 2001; Amoros et al., 2006).

Age did have an effect, although it was not significant for each category. The higher the age category, the higher the odds ratio was for all categories above 29, with the age group 15-29 as a reference category. For the age group below 15, the odds ratios delivered no clear picture. The increased severity for higher age categories corresponds with existing knowledge (Bédard et al., 2002; Evans, 2004).

Possible differences in the reporting rate could again provide an alternative explanation for the stated effect of age. Amoros et al. (2006) found a slight association between age and reporting rate with a somewhat higher reporting rate for older age categories. Other studies found no effect for age, but used smaller samples (Daniels et al., submitted) or found only a lower reporting rate for the age category 0-14 (Alsop \& Langley, 2001) which is likely to have some alternative explanation, although these last authors controlled for road user type. If the reporting rate for crashes with subjects in younger categories in our sample would be somewhat lower than for older subjects, this would mean that the reported severity of the crashes with younger subjects in our sample tends to be somewhat overestimated in comparison with the severity for the older subjects' crashes (under the assumption that the most severe crashes are more correctly reported, regardless of the age category). In that case, the stated effects for age in Table 8 seem even to be underestimated. Anyway, a slight difference in reporting rate is not likely to affect the stated effects of age.

\section{Light conditions}

The stated results in Table 8 show a tendency toward more severe crashes at night. Obviously, this variable could act as a confounder for some other, unobserved but correlated variables such as differences in speeds (for instance due to less busy traffic conditions), in travel purposes or in driver 
characteristics at night. Other possible explaining variables that are likely to be different are present in the model and are therefore controlled for: road user type, alcohol use, age and gender. Again, the reporting rate might be influential as well. Amoros et al. (2006) found an estimated significant 9\% higher probability for crashes at night to be reported compared with daylight crashes. But if this estimation would be valid for our dataset and assuming that more severe crashes are more correctly reported, regardless of their time of occurrence, the stated effect in Table 8 would only be reinforced.

\section{Built-up area}

The logistic regression results show that crashes inside built-up areas are significantly less severe than crashes outside the built-up area. Differences in reporting rate are not very likely for this variable. The most likely interpretation for this result seems that the distinction inside versus outside the built-up area correlates with other, not incorporated variables. Since mainly approaching speeds at roundabouts are expected to be much lower inside then outside built-up areas, this seems to be a plausible factor.

\section{CONCLUSIONS}

To sum up, the following conclusions can be made:

- A clear externality of risk seems to be present in the investigated dataset. The crash severity is strongly dependent of the involved types of road users. Pedestrians, bicyclists, moped riders and motorcyclists have a higher probability of getting seriously injured in a crash. Bicyclists represent almost the half of all the killed or seriously injured in multiple-vehicle collisions at the investigated roundabouts.

- Fatalities or serious injuries in multiple-vehicle crashes for drivers of four-wheeled vehicles at roundabouts are relatively rare.

- A higher age does increase the probability of a severe or fatal injury. This result corresponds with existing knowledge. 
- Crashes at night and crashes outside the built-up area turn out to be more severe. Correlations of these variables with unobserved but important variables, in particular with impact speeds, might be present and explain their role in the models better.

- Systematic differences in the reporting rate of crashes according to road user type, the number of involved road users and crash severity are likely to exist and may cause the stated results to be under- or overestimations of the real effects on crash severity. Particularly prone to a bias due to a different reporting rate, are the more severe outcomes for single-vehicle crashes. It is therefore impossible to conclude whether single-vehicle crashes were in general more severe or not. Other results, such as the effects of the road user type, age, geometry and light conditions are less likely to be substantially influenced by a different reporting rate.

- Future research on injury would benefit from more detailed data on impact speeds of vehicles when crashing, data on the exact location of the crashes at the roundabouts (entry, exit lane, roundabout itself) and collision diagrams showing impact points and impact angles.

\section{REFERENCES}

Agresti, A. (2002). Categorical Data Analysis. WILEY SERIES IN PROBABILITY AND STATISTICS (2nd ed.). Hoboken, New Jersey: Wiley-Interscience.

Alsop, J., \& Langley, J. (2001). Under-reporting of motor vehicle traffic crash victims in New Zealand. Accident Analysis \& Prevention, 33(3), 353-359.

Amoros, E., Martin, J., \& Laumon, B. (2006). Under-reporting of road crash casualties in France. Accident Analysis \& Prevention, 38(4), 627-635.

AWV (2008). Verkeerstellingen 2007 in Vlaanderen met automatische telapparaten. Brussel:

Ministerie van Mobiliteit en Openbare Werken - Agentschap Wegen en Verkeer, http://www.wegen.vlaanderen.be/documenten/tellingen/2007 (accessed August 6th, 2009).

Bédard, M., Guyatt, G. H., Stones, M. J., \& Hirdes, J. P. (2002). The independent contribution of driver, crash, and vehicle characteristics to driver fatalities. Accident Analysis \& Prevention, 34(6), 717-727. 
Daniels, S., Brijs, T., \& Keunen, D. Official reporting and newspaper coverage of road accidents: a case study. Submitted.

Daniels, S., Brijs, T., Nuyts, E., \& Wets, G. (2010). Explaining variation in safety performance of roundabouts. Accident Analysis \& Prevention, 42, 393-402.

Daniels, S., Brijs, T., Nuyts, E., \& Wets, G. (2009). Injury crashes with bicyclists at roundabouts: influence of some location characteristics and the design of cycle facilities. Journal of Safety Research, 40(2), 141-148.

Daniels, S., Nuyts, E., \& Wets, G. (2008). The effects of roundabouts on traffic safety for bicyclists: an observational study. Accident Analysis \& Prevention, 40(2), 518-526.

Elvik, R. (2003). Effects on Road Safety of Converting Intersections to Roundabouts: Review of Evidence from Non-U.S. Studies. Transportation Research Record: journal of the Transportation research Board, 1847, 1-10.

Elvik, R. (2008). Dimensions of road safety problems and their measurement. Accident Analysis \& Prevention, 40(3), 1200-1210.

Elvik, R., \& Mysen, A. (1999). Incomplete Accident Reporting: Meta-Analysis of Studies Made in 13 Countries. Transportation Research Record: Journal of the Transportation Research Board, 1665(-1), 133-140.

European Commission. (2006). CARE - Glossary. European Commission. Retrieved December 10, 2009, from http://ec.europa.eu/transport/road_safety/observatory/statistics/care_en.htm.

Evans, L. (2004). Traffic Safety. Bloomfield Hills, Michigan, USA: Science Serving Society.

Evans, L., \& Frick, M. C. (1993). Mass ratio and relative driver fatality risk in two-vehicle crashes. Accident Analysis \& Prevention, 25(2), 213-224.

FOD Economie. (2009). Verkeersongevallen- en slachtoffers. Federale Overheidsdienst Eonomie, K.MO., Middenstand en Energie. Retrieved December 10, 2009, from http://statbel.fgov.be/nl/statistieken/cijfers/verkeer_vervoer/verkeer/ongevallen_slachtoffers/in dex.jsp.

Goldstein, H., Browne, W., \& Rasbash, J. (2002). Partitioning Variation in Multilevel Models. Understanding Statistics, 1(4), 223.

Hauer, E. (2006). The frequency-severity indeterminacy. Accident Analysis \& Prevention, 38(1), 7883.

Kim, D., Lee, Y., Washington, S., \& Choi, K. (2007). Modeling crash outcome probabilities at rural intersections: Application of hierarchical binomial logistic models. Accident Analysis \& Prevention, 39(1), 125-134. 
Persaud, B., Retting, R., Garder, P., \& Lord, D. (2001). Safety Effects of Roundabout Conversions in the United States: Empirical Bayes Observational Before-and-after Study. Transportation Research Record: Journal of the Transportation research Board, 1751, 1-8.

Schipper, Y., Rietveld, P., \& Nijkamp, P. (2001). Environmental externalities in air transport markets. Journal of Air Transport Management, 7(3), 169-179.

Shinar, D. (2007). Traffic Safety and Human Behavior. Amsterdam: Elsevier.

Verbeek, M. (2004). A guide to modern econometrics. John Wiley and Sons Ltd.

Waller, P. F., Stewart, J. R., Hansen, A. R., Stutts, J. C., Popkin, C. L., \& Rodgman, E. A. (1986). The Potentiating Effects of Alcohol on Driver Injury. JAMA, 256(11), 1461-1466. 